\title{
Holy Amnesia: Remembering Religious Sages as Super Humans or as Simply Human
}

\author{
Yohai Hakak
}

Received: 1 July 2008/ Accepted: 18 January 2009

(C) Springer Science + Business Media B.V. 2009

\begin{abstract}
The last decade has witnessed a wave of Haredi literature dealing with the education of children and youth in particular. A common question raised in this literature is that of the proper way to describe the Torah sages of previous generations, i.e., what needs to be remembered and what should be forgotten about them. Many of the writers criticize the ways of writing customary up to our time, which tended to describe Torah sages as superhuman and as lacking any weaknesses or failings; raising educational concerns, they call for a change in these ways of portrayal. In this article, I apply Mary Douglas's theoretical model of "enclave culture" to the current social circumstances of the Haredi community, in an attempt to explain both the origins of this trend as well as the sources of opposition to these new ways of writing history within the Haredi community.
\end{abstract}

Keywords Memory $\cdot$ Haredim $\cdot$ Yeshivas $\cdot$ Education

In 2002, Rabbi Nathan Kamenetsky's book Making of a Godol ${ }^{1}$ was published. The title of the book suggests the writer's intention to demonstrate that even the greatest

\footnotetext{
${ }^{1}$ Godol is the Yiddish pronunciation for the Hebrew word gadol which means "great" and is used to indicate the great Torah sages.

Haredi is the singular for Haredim - the Haredi Jews. The verb hared in Hebrew means to tremble and comes from the book of Isaiah (66:5): "Hear the word of the LORD, you who tremble at his word." I employ the Hebrew term "Haredi" (rather than Ultra Orthodox) because this is the term used by members of the community to refer to themselves, and because it is a broader classification which encompasses not only the Eastern European groups; see, for example, Friedman [The Haredi society: Sources, trends and processes. Jerusalem: The Jerusalem Institute for Israel Studies (Hebrew), 1993].
}

Y. Hakak $(\bowtie)$

School of Health Sciences and Social Work, University of Portsmouth, Portsmouth, UK

e-mail: yohai.hakak@port.ac.uk 
Torah sages did not come into the world with all the attributes of greatness, but rather went through a long process of struggle with human difficulties and weaknesses. The book raised a storm and within a short time was banned. The great Torah sages of Israel, headed by Rabbi Yosef Shalom Eliashiv, ${ }^{2}$ demanded that the author cease its distribution. ${ }^{3}$ In a letter banning the book, signed by the greatest Lithuanian $^{4}$ rabbis in Israel, the book is described thus:

It is full of grave humiliations, flippancies, and mockeries and creates a bad name for some of our greatest rabbis who are the holiest of the luminaries of Israel of the last generations. For they are the 'ancients [who are] like angels' and from their words all Israel lives [...] and the greatness of their honour and holiness is rooted in the heart of every God-fearing Jew. And this book seeks to abolish this through slander, disgrace and humiliation of their glorified honour, which is also the honour of our blessed God and our holy Torah. ${ }^{5}$

According to traditional Jewish belief, "the ancients are like angels" (Tractate Shabbat 112 b), i.e., the qualities of humankind - and thus the ability to understand the Holy Scriptures-decline in the course of the generations. Hence, rabbis of previous generations are considered as much wiser and holier than those of the present, and should be treated accordingly.

This vitriolic letter is directed, not at a slanderous document, but against a book written by Rabbi Nathan Kamenetsky, son of Rabbi Ya'acov Kamenetsky, who headed Yeshiva ${ }^{6}$ Torah ve Da' at in New York, and is considered one of the greatest Lithuanian Torah sages of the second half of the twentieth century. Although Rabbi Nathan Kamenetsky's description of Haredi rabbis is full of appreciation, the freedom he adopts in discussing various aspects of their lives was considered unacceptable. ${ }^{7}$ It seems that the book provoked discussion on the issue of what is acceptable to write, commemorate, and remember, and what, on the other hand,

\footnotetext{
${ }^{2}$ Rabbi Yosef Shalom Eliashive, presently well into his nineties, is the paramount leader of Israel's Lithuanian non-Hassidic Haredi Ashkenazi Jews (sometimes called by the old label "misnagdim") who regard him as "the generation's legislator," the contemporary leading authority on halakha, or Jewish law.

3 The name of the book evokes critical connotations, as if to deconstruct how society creates its luminaries. Following the banning of his book, Kamenetsky (2003) wrote another book, Anatomy of a Ban, in which he analyzes the events that led to the banning of his book. The name of this book, too, like the previous one, indicates a critical, reflective view of topics that are not usually discussed.

${ }^{4}$ Lithuanian Jews, known in Yiddish and Haredi English as Litvish (adjective) or Litvaks (noun), are Ashkenazi Jews with roots in the Grand Duchy of Lithuania (present-day Belarus, Lithuania, Latvia and the northeastern Suwałki region of Poland). Lita was historically home to a large and influential Jewish community that was almost entirely eliminated during the Holocaust. Before World War II, there were over 110 synagogues and ten yeshivas in Vilnius. The characteristically "Lithuanian" approach to Judaism was marked by a focus on highly intellectual Talmud study; this still dominates "Lithuanian yeshivas" today, even though they are located in Israel and in several other countries.

5 The letter announcing the ban was published in the Anatomy of a BanYated Ne'eman newspaper, identified with the Lithuanian sector. A photograph of it appears in the appendix to Rabbi Kamenetsky's book Anatomy of a Ban, together with other documents connected to the issue.

6 A Yeshiva is a Jewish religious seminary.

7 Rabbi's Kamenetsky's book is obviously not the first Haredi book to be banned, but I choose to focus on it is an excellent case study for the sensitivities involved.
} 
should be omitted and forgotten. Over the last decade, in addition to Rabbi Kamenetsky, other Haredi rabbis and educators have raised this issue, voicing penetrating criticism of the ways in which the Torah sages of past generations were portrayed hereto.

In this article, I will present the manner in which Torah sages were traditionally portrayed and examine the reasons for it. I will also inquire into the causes of the growing demands for different styles of representation and recollection of the sages, and how such demands might engender alternative modes of representation and recollection.

This article continues my previous ethnographic research on Lithuanian yeshivas in Israel (Hakak 2005, 2006). As part of that research, I read many educational guides written by Haredi rabbis and educators for youth, their parents and teachers. This literature provides good access to current Haredi educational discourse on these issues. I was directed to many of these books by yeshiva students and Haredi educators, while I came across others by searching in Haredi book stores. I focused on those guides which according to my informants were the most popular and widely accepted. The majority of the guide books I will review were written in the last decade. In some cases, I also interviewed the authors. This literature will be at the center of my analysis and parts of it will be presented here. While the discussion of the description of Torah sages is led by Lithuanian rabbis, in recent years rabbis from other Haredi sectors have taken part as well.

It is impossible to understand the new demands for different descriptions of Torah sages without taking into consideration the social and historical context in which they have appeared. Several researchers have examined the social changes taking place within the Israeli Haredi community in recent decades, especially since the early 1990s (Elor 1992; Elor and Neria 2003; Goodman 2003; Gonen 2000; Horowitz 2002; Friedman 1991; Shtadler, 2001), pointing to its demographic growth, political rise, and geographical expansion. They have also indicated its growing integration into Israeli society. It is clear that the Haredi community is no longer a small minority, as it was in the years following the establishment of the State of Israel; it is a flourishing and self-assured community, which is gradually expanding and steadily increasing its achievements and influence. One of its main achievements is the exceptional growth of the world of Israeli yeshivas, enabled by the modern welfare state, and which has become the largest group of Torah scholars in Jewish history, located in one geographical area (Breuer 2003). This growth was possible due to the rabbis' success, after the establishment of the State of Israel (1948), in transforming yeshiva studies from an elite route for the very few into a mass education route for all young Haredi men (Friedman 1991).

Yet over the last decade, it has been undergoing major change and crisis: thousands of men are leaving the yeshivas for other arenas of activity, such as occupational training programs and the labor market; poverty rates are also very high and the number of Haredi welfare organizations is growing rapidly. Massive cutbacks in the subsidies transferred by the state to the Torah institutions and their students have increased the threat that many more students may be forced to leave the yeshivas. Outside of those structures, Haredi leaders fear, the young men would 
be exposed to the dangerous, contaminating influence of the outer-non-HarediWestern, modern world. The fear of social disintegration is fueled by the growing dropout rates from Haredi yeshivas, a phenomenon which barely existed 15 years ago. 8

\section{Defection, Authority, and the Enclave Culture}

In order to analyze the above-mentioned changes I will now employ the theoretical model of the "enclave culture," as developed by the anthropologist Douglas (1993). In her work, Douglas emphasizes the connection between the social structure and the cosmology, culture, and values of each society. The enclave is one of three ideal social structures cited by Douglas, alongside the hierarchical society and the individualistic society. The enclave is a community that chooses to disengage from mainstream society, and therefore forfeits substantial access to the resources of its government. As it is incapable of employing government authority in order to enforce its rules on members of the enclave, and is also unable to compete with the rewards and resources of mainstream society, the enclave is constantly threatened by the possibility of its members' defecting to mainstream society, and consequently must invest tremendous efforts to prevent this (Douglas 1993, p. 53).

In order to preserve its hold over its members, the enclave makes intensive use of moral discourse that distinguishes the outside_-presented as threatening, dark, and negative-from the enlightened, pure, and positive inside. This effort is supported by the enclave's frequent evocation of past events which explain the community's unique historical origins and narrative, while emphasizing assaults and persecutions carried out by the "outside" community (Douglas 1986, p. 80). Another way to prevent defection, according to Douglas, and more central to this article, is through promotion of equality among members of the enclave and the creation of a type of Utopian society in "this world," in which the deep (spiritual) desires and needs of all members of the community are presumed to be satisfied. Hence, the outside may also be portrayed as divided between the exploiters and the exploited, while the inside remains egalitarian and respectful.

\section{Historical Writing and the Jewish Religion}

In order to understand the call for a different historical description of the Haredi Torah sages we must first examine the attitude of Judaism in general, and Haredi society in particular, to the pursuit of historical writing. According to Yerushalmi (1982), for many centuries Judaism regarded the pursuit of historical writing as insignificant; and on the whole, historical writing was absent in it. On the one hand, God revealed Himself to the Israelite nation through His actions throughout history,

\footnotetext{
8 They made up $7.7 \%$ of the student population in $2001-2002,8.3 \%$ in $2002-2003$, and $7.9 \%$ in $2003-$ 2004. The percentage of secular and religious students who dropped out during those years is much smaller. For example, in 2001-2002 they comprised 4.5\% of the secular student population and $4.8 \%$ in the religious sectors (Lahav 2006).
} 
as in the Exodus from Egypt. Thus, remembering certain historical events has always been an important factor in Jewish practice and identity. On the other hand, the historian was not the one entrusted with the recording and transmission of that past. The components of the past considered worthy of remembrance are the deeds of the Lord and man's positive and negative reactions to them. The Lord is in fact the real hero of this history (Yerushalmi 1982).

Greenfield (2004) provides a possible explanation for this tendency. She discusses traditional societies that are

characterized by the fact that they assume that the eternal desire of God...and therefore the only possible truth is revealed only in fixed categories that do not ever change. The fixed is the godly and all that is changeable and therefore finite cannot be godly, and by necessity cannot be genuine (Greenfield 2004, p. 89).

In these terms, historical enquiry is an enquiry into all that is not genuine and is hence superfluous. Yerushalmi's thesis was challenged by Funkenstein (1993), who claimed that Yerushalmi overstated the gulf between history and memory. Funkenstein proposed a third category, historical consciousness, to temper Yerushalmi's opposition between historiography and collective memory (Moyn 2003).

The substantial change in historical writing came about only with the modern era following the permeation of Enlightenment influence into traditional Jewish society (Karlinski 1998, p. 99). Consequently, orthodox Jewish historical writing or, as its researchers called it, "orthodox historiography" developed (Assaf 2006; Bartal 1984, 1998). According to Assaf, this kind of writing is no different from other branches of "ideologically oriented history" or any history "in the name of...". Inherent in this kind of writing is

a recruiting "agenda" that seeks to promote certain perceptions, explanations or values and regulate by varied methods the ability of the antagonist or the rival to voice his claims fairly. This kind of writing does not consider the research of the truth or the reconstruction of the past "as it was" as an aim in itself... but rather as an extra tool for the promotion of an agenda and for combating rivals (Assaf 2006, p. 25).

One of the few original Jewish genres that does constitute a form of historical writing is that of the "Kabala dynasties." In this case, the Hebrew word Kabala refers, not to Jewish mysticism but to its literal meaning, "to receive." This genre was created as a reaction to those who negated the Oral Torah, providing proof of the unbroken continuity of sages transmitting the revelation from Mount Sinai down to the Torah legislators of the contemporary period. This literature was biographical in character and was one of the predecessors of more modern biographical writing, starting with the traditional Jewish society and continuing in Haredi society (Karlinski 1998, p. 121). Describing the expansion of the traditional Jewish and Haredi bookshelves over the last generations, Breuer (2004) mentions writings on the life stories of Jewish sages, leading rabbis, and heads of yeshivas. In his words, 
this branch of Haredi literature grew out of the Hassidic ${ }^{9}$ sphere, where it was first known as "In Praise of the Saints" and later gained currency among the "resistant" Lithuanian stream. The life story of famous yeshiva heads was offered as important spiritual food for thought for old and young, men and women alike. ${ }^{10}$

Like other forms of Haredi historical literature, this genre also differs significantly from non-Haredi biographical writing. Whereas other biographical writing may utilize sociological, psychological or other tools in order to come to conclusions relevant to the present day or for the sake of knowledge itself, Haredi writing is primarily didactic. Whatever does not serve the "proper" aims or is seen as undermining them will not find its way into the text and will be silenced. This tendency was recently very well described by Yoel Finkelman, who analyzed American Haredi historical literature. He shows how the nostalgic and idyllic portrayals of Jewish life in Eastern Europe serve the need to portray current America as dangerous to the religious survival of the community, and thus the emphasis on segregation. The Haredi historical descriptions of rabbis from past generations should inspire the community to follow their steps and withdraw from the temptation American society offers them (Finkelman 2008b).

\section{The Haredi Education System's Picture of Reality}

The traditional mode of description of the characters of Torah sages is embedded in wider educational discussion on the proper picture of reality to portray and present. I will mention here two guiding principles. According to the first, good education must present a world picture that is clear and simple enough for the child and the youth to understand. Once the child has internalized this simple world view it may be possible to render it more complex over the years, although this issue hardly seems to concern the writers of the educational texts that were examined for this article. The second principle has wider implications and is part of the Haredi cultural model-not only the educational. According to this principle, students should be imbued with religious ideals even if only very few of them can fulfill them all. According to the Haredi perspective, life with ideals set by God-even if unattainable for most-is better than life guided by mediocre human norms and goals. To distinguish between those who sin out of weakness and those who sin out of principle, Halachic literature distinguishes between the "epicurean by appetite" and the "epicurean out of spite." Although it is clear that many will not be able to

\footnotetext{
9 The word Hassidic comes from the Hebrew word Hassidut meaning "piety." Both words come from the Hebrew root word hessed meaning "loving kindness." The Hassidic movement is a Haredi Jewish religious movement. Some refer to Hassidic Judaism as Hassidism, and employ the adjective Chasidic/ Hassidic. The movement originated in 18th-century Eastern Europe.

${ }^{10}$ Kamenetsky outlines the opinions of various rabbis (2002, pp. 10-15) on the matter. While he indicates that several rabbis objected to biographical writing that focused on a single person and saw it as a waste of time that could be better spent studying Torah, anthologies on the lives of Torah sages enjoyed a far more positive status. Kamenetsky cites a variety of sources that emphasize the obligation to write in praise of Torah sages.
} 
fulfill all the religious ideals, it is expected that they will keep their failures to themselves (viewing them as weaknesses due to human "appetite"), and will certainly not display them; consequently, hypocrisy and concealment become part of the routine (Roze 2006).

The following quotes from the books I analyzed will further clarify these principles. The quotes deal with an issue closely related to our discussion: how should "members of our crowd" be described? The following is an excerpt from Rabbi Moshe Klatzkin's ${ }^{11}$ book (2004, p. 122), in which he discusses the appropriate way to negate wicked acts:

In principle, one should avoid employing the second person when warning children in advance against doing negative things. Frankly, in using this form we are granting legitimacy for such a possibility. Even when talking about a negative act in general. We discuss the gravity of theft and warn against it. We thus suggest that we suspect them, and that they are capable of performing such an act-as if the possibility exists for an incident like this to occur among them. It must be clear to every child that we do not entertain the slightest thought in that direction[...]instead, we should transmit with full confidence: "You are righteous and good, all of you are honest and just!" [...] The opportunity to speak of the bad, denounce and totally nullify it arises in speaking of those who are not of us: when telling of evil men that once werea drunken, contemptible gentile who stole, and whom everyone despised and condemned. Amongst us, such things don't exist...

Rabbi Klatzkin's writing proclaims that speaking of negative actions in the present creates such behavior as an option. The rabbi suggests restricting the discussion of such actions to those who are not "members of our crowd," in other words- "others," "evil people," "gentiles," etc. Such talk creates and strengthens a dichotomous world view in which all "members of our crowd" are pure and pristine whereas the outside is evil, defiled, and dangerous. But while Klatzkin's reasoning emphasizes the cognitive aspect and tries to eliminate even the mere possibility that the child may choose a negative action, other writers offer other explanations for this educational practice. Rabbi Avraham Yaacov Levi, ${ }^{12}$ for example, emphasizes emotional aspects with regard to this issue:

The parents should show their children how successful they are and that, with the grace of G-d, they see blessing in their toils [...] And in general, they should demonstrate how piety has the upper hand and that the people of Israel are very strong $[\ldots]$ And whoever follows the Torah succeeds, while those who tried a different path returned to the path of the Torah, as it is full of light and joy; for there is nothing like the joy of Torah. These feelings attract the

\footnotetext{
${ }^{11}$ Rabbi Moshe Klatzkin, who belongs to the Jerusalem Hassidim group, is the head teacher of Zikhru Torat Moshe Talmudei Torah Network whose schools serve mainly the Lithuanian sector, with several directed towards the Hassidic sector. The Jerusalem Hassidim dress like Hassidim, but have no Hassidic rabbi, and in many respects behave like Lithuanian Haredim.

${ }^{12}$ Rabbi Avraham Yaacov Levi is a Hassidic educator who teaches in a small yeshiva of the Bian Hassidic group in Jerusalem. .
} 
child, who can see himself as part of something enormous and strong, part of something very successful, and this raises his confidence in his belief that he is as accomplished as those around him. That is why it is befitting that parents hide their failures and those of people who follow the Torah from their children, so that they may award those who follow the Torah an image of success, joy, and happiness (Levi 2001, pp. 24-25).

In order to depict the world of the adults who follow the Torah as attractive, this writer promotes its description in optimistic and positive colors, while concealing the parents' failures and "sins." Such a description will stimulate intense feelings, which will attract the hearts of the youngsters and motivate them to follow in their parents' footsteps.

\section{The Torah Sages-Exemplary Adults}

In many cases, the laudatory description of Torah sages and important rabbis of previous generations was based on similar assumptions. An example of this tendency can be found in the book by Rabbi Avraham Yaacov Levi mentioned previously, in which he advises (2001, pp. 79-80):

And then the homeroom teacher should ignite the desire of the youth to utilize his qualities in accordance with his Creator's wishes [...] He shows him the attraction and the joy in persistence in the study of the holy Torah. The courage and bravery of Torah leaders throughout the generations, their great success in this world, and their lasting imprint on our memory should always be an example, respected by all mankind and in every way. The youngster is usually not aware of the difference between them and himself, and imagines that he too is really like them and yearns to be like them and thereby awakens his desire to emulate their attributes so that they may serve him.

The description of Torah sages of previous generations has primarily an educational role. They are intended as a source of inspiration, models to emulate, and to enable this, it is necessary to describe their "courage and bravery" and "the success of greatness in this world."

Kamenetsky (2002), himself a member of the Lithuanian stream, differentiates between Hassidic writing of "tales" about the great men of previous generations, and historical writing faithful to the truth. In the lengthy introduction to his book Making of a Godol he brings evidence of conflicting opinions between rabbis regarding the correct and preferred way to describe the sages of previous generations. More than discussing the differences between the writings of Hassidic and Lithuanian streams on the subject, Kamenetsky shows the extent to which Lithuanian rabbis themselves disagreed over this issue. He presents the conflicting attitudes on the subject of two brothers, renowned in the Torah world. One was Rabbi Shimon Schwab, ${ }^{13}$ who defined the differences between historical writing and recounting tales. Historical writing should be:

\footnotetext{
13 Rabbi Shimon (Simon) Schwab (1908-1993) was an Orthodox rabbi and communal leader in Germany and the USA, initially in Baltimore and later in Washington Heights in New York City.
} 
Truthful, and unsparing of even the failings of the righteous... A realistic historic picture [will reveal] inadequacies [that will] rightfully make many people angry[...] No ethical purpose is served by preserving [such a picture].

He contends that we must "put a veil over the human failings of our forebears and glorify all the rest which is great and beautiful." He adds: "we do not need realism: we need inspiration from our forefathers" (Kamenetsky 2002, p. xxiv).

Immediately thereafter, Kamenetsky presents the brother's comments, those of Rabbi Mordechai Schwab. This brother had reservations about the tales and, in conversation with Rabbi Kamenetsky, mentioned that the Satmar rabbi, Yoel Teitelbaum, ${ }^{14}$ never told such tales and often said that "one cannot educate through lies." Kamenetsky then provides several examples of reservations on the part of Lithuanian Torah scholars to concealing or distorting the truth when telling stories of the sages. These examples notwithstanding, it is fairly clear that, whereas in the Hassidic sector the tendency to embellish reality and obscure less pleasant aspects of the characters of Torah sages is particularly strong (Assaf 2006), it is apparent in the Lithuanian stream as well (Assaf 2006, p. 24, footnote 14). Everything that does not serve the educational objective is not relevant and should not be mentioned. But what exactly are those details that, until now, were considered right to be deleted and forgetten in the description of the "sages"?

\section{Reducing the Material Dimensions: The Soul Strives for Its Supreme Source}

According to the ideal Haredi cultural model, the purpose of man, especially Jewish man, is to dwell near God, develop his love for Him, and to adhere to Him. But the path to loving God is complex and passes through body and soul, which struggle between themselves. The soul is a "Heavenly part of G-d" and is therefore by nature closer to Him; the body, in contrast, is "material and separate by nature from its roots." In this regard Rabbi Moshe Haim Luzzato $(2001)^{15}$ writes in his book Mesillat Yesharim (Path of the Just):

Superior intelligence decreed that man be composed of two opposites, i.e. of a pure intellectual soul and a lowly, earthly body, each of which will pull in its own direction, i.e., the body to materialism and the soul to spiritualism. And there shall be a struggle between them etc., for man has the ability to subject his material [facet] before his intellect and soul[...] But if man allows the material to win, the body will be degraded and with it, his soul ("The Route of God", Sect. 1, p. 83).

\footnotetext{
${ }^{14}$ Satmar is one of the largest Hassidic dynasties, originated in the town of Szatmárnémeti (now Satu Mare, Romania) which, until World War II, was in the Kingdom of Hungary. Rabbi Teitelbaum, who headed the Satmar Hassidic group up to 1979, was probably the best known Haredi opponent of all forms of modern political Zionism.

${ }^{15}$ Rabbi Moshe Chaim Luzzatto was a prominent Italian Jewish rabbi, kabbalist, and philosopher. He is mostly remembered today through his ethical treatise Mesillat Yesharim (Path of the Just).
} 
The body and the soul are polar opposites - the one celestial and the other earthly and lowly. Man has the ability to choose between good and evil, in other words, between the victory of the evil inclination (and that of the earthly and lowly body), and the victory of the good inclination, which is the victory of the intellectual soul. This choice is essential en route to realizing man's spiritual destiny.

When human beings arrive in the world, the force ruling them is the body, but gradually, especially after age 13, youths are to struggle against the demands of their bodies, to impose their intellectual souls upon them and to choose the good. This approach is also articulated in a book by Rabbi Nachman Yossef Wilhelm (1993), ${ }^{16}$ written as a guide to Haredi youth of Bar Mitzvah age. ${ }^{17}$ In the introduction, Wilhelm describes the fateful importance of the day of the Bar Mitzvah ceremony, symbolizing the transition from childhood to adolescence:

...The great day in your life, when you become a "man" and a reasoning person, accepting the burden of Torah and the commandments and joining the ranks of the multitudes of the Children of Israel....True, the period of childhood has ended, the period of training and education that you trod hand in hand with your parents who sheltered you in the shadow of their wings.... Today you set out on a long road with many opportunities, challenges and tasks....But even greater is the next day, when you begin your life of action, a life of work and effort, studying the Torah and conversing in prayer, breaking down and refining your character attributes, struggling with the evil inclination that never ceases its labor.

Several pages thereafter, Rabbi Wilhelm adds: "Till the thirteenth year man deals with his body, with his bestial soul; from the thirteenth year and thereafter, if he wants to be innocent, he is given a primal celestial soul taken from the King's Throne of Honor."

Rabbi Wilhelm portrays a sharp transition from boyhood to manhood, without an interim adolescent period. But this description seems intended mainly to underline the importance of the event for the youth. Many references made by Haredi rabbis demonstrate a more complex attitude towards the transition from childhood to adolescence, including recognition of the gradual development of inner restraint and discipline.

While secular Israeli youth are expected to prove their physical prowess and their ability to cope with effort and bear suffering-whether during their basic military training or through previous trials-yeshiva youth are constantly expected to prove their ability to restrain and control their bodies, their cravings, their impulses, and their feelings. Since the evil inclination does not rest for a moment, Haredi youth

\footnotetext{
${ }^{16}$ Rabbi Nachman Yossef Wilhelm is an educator from the Slonim Hassidic group and the spiritual supervisor of Yeshivas Hazon Nachum Yoel in Bnei-Brak. He is the author of a series of books on various educational issues which met with great success in the Haredi community.

17 Bar Mitzvah ("son of the commandments") is one to whom the religious commandments apply. According to Jewish law, when Jewish children reach the age of majority (generally 13 years for boys and 12 for girls) they become responsible for their actions, and become a Bar or Bat Mitzvah.
} 
must constantly be on guard lest they lose their masculinity. ${ }^{18}$ This threat accompanies them throughout life.

The centrality of the struggle with the material dimensions of life is expressed in a book written by a young Israeli yeshiva student, Karlinski $\left(2004\right.$, p. 67) ${ }^{19}$ :

I investigated and found that all the places in the world are divided into two types, as separate from each other as light is from darkness. These are the "good" and the "bad"....Without this, other divisions are merely the result of chance, time and society, or of some innate characteristic... bestowed on them by the Creator[...]. The only thing distinguishing human beings from each other is their classification-who among them is superior in the battle between the spiritual and the material. This fortitude is a person's life creation. That is the "it"....This domain alone is in his hands, as he is a free agent, to impose the intellectual emotion on the lustful emotion....

Every other division, bar that which differentiates between the material and the spiritual, is marginal. The extent to which a person can impose his intellect on his lust and on the body is his greatest life creation. This approach characterizes all of Haredi literature but is presented here in sharp relief. Furthermore, in order to succeed in abolishing the power of the body, man should distance himself as far as possible from the material aspects of life. The degree of asceticism suitable is defined by Rabbi Moshe Haim Luzzato in Mesilat Yesharim: "He should quit everything inessential for a person regarding this world [...]. But everything he needs for any reason, since he needs them-if he gives them up, he is a sinner" (Sect. 13).

These words refer not only to bodily needs, which should be limited as far as possible without harming healthy bodily functioning, but to all possible material and earthly activities other than the study of the Torah and the observance of the commandments. ${ }^{20}$ Accordingly, every involvement with the material world that is not essential for performing God's work and the commandments is perceived as the success of the evil inclination (Shlanger 2001, p. 41). Feelings such as pride, anger, and laziness are considered negative manifestations with which one should struggle, all the more so sexuality, aggression, and avarice. These and other feelings are termed "attractions of the heart" or "attributes" in yeshiva language, on which one must "work." Most of them are associated with the relations between people, but some of them, such as sexuality, are also associated with the relationship between man and God.

But apart from avoiding "doing evil" through controlling and disciplining bodily urges and reducing material dimensions, the spiritual elevation of the individual also necessitates "choosing good," i.e., investing all efforts in observance of the commandments, and primarily the study of the Torah. Assessing the talents and achievements of Haredi youth therefore comprise two variables: the degree of discipline the youth have managed to internalize in order to harness their bodies to

\footnotetext{
${ }^{18}$ See also Satlow (1996) in this context. On masculinity as an unstable identity see Chodorow (1974).

${ }^{19}$ Karlinski died in tragic circumstances and has been described posthumously as a genius. His family published some of his letters and essays after his death.

${ }^{20}$ Work to finance the family, involvement in public affairs, military service, etc. will be included in this definition.
} 
perform the commandments, and their achievements in the study of the Torah. These variables are extremely important, particularly during the transition from the yeshiva for youngsters to the yeshiva for adults around the ages of 16-17 years, as well as in determining their social status and the rabbis' attitudes towards the students. This cultural model also shapes the desired image of Torah sages and the way in which Torah sages are portrayed in their biographies. Torah sages are perceived as those who succeeded admirably in reducing and restraining the presence of material dimensions in their lives while expanding the spiritual dimensions in their lives through maximum immersion in the study of the Torah and the performance of its commandments.

\section{Reducing Earthliness in the Israeli Context}

Several factors, which are a part of the Israeli context, add to the difficulties of some of the students in controlling and disciplining the body according to the ideal Haredi cultural model. In order to enable the reduction of materialism while secularism is breathing down its neck, offering a variety of temptations (Sivan 1991; Almond et al. 2003), ${ }^{21}$ Haredi society depicts "protected spaces" with as few threatening stimuli as possible. In these spaces, Haredi men can devote time to involvement in spiritual issues, i.e., to study the Talmud. As part of that process of constant differentiation between pure and impure, dichotomies are constructed between the protected, spiritual and pure "yeshiva," and the impure, licentious, libidinous, and dangerous "street." 22

In spite of the considerable effort invested by the yeshivas in creating this protected space, obstacles have accrued in recent decades whose influence only grows. The establishment of yeshiva learning as an obligatory norm for all Haredi youth successfully halted defection from Haredi frameworks in the face of the attractions of a triumphant Zionist ideology. But by blocking all exits, and forcing all Haredi youth to remain in yeshivas, including those who are unsuitable or lack interest, inner stability and order are threatened (Friedman 1991).

Added to this is the increasing power of the Haredi public from the political, social, and demographic perspectives. As a consequence, the growing selfconfidence of Haredi society and its youth acts as a counterweight to the effort to limit these youngsters and minimize their access to the Israeli public domain. Shortly after the establishment of the State of Israel the Haredi community was a

\footnotetext{
21 Secular society has also changed in the last few decades with the weakening of the great ideologies. Capitalist debate and consumer culture, which encourage giving increased legitimacy to bodily needs and has reservations regarding the restrictions and reduction of the earthly aspects, were more feasible. Although the body is carefully disciplined in the framework of this world perspective, the aim is to make it into an object of greater passion.

22 Thus, for example, Rabbi Shach (1993) describes the importance of Yeshivas in current reality: "Nowadays the Yeshivas have an additional role apart from teaching Torah and the fear of God, as they serve as protection from the calamities lurking at every street corner.... The street has lost its human form. There is emptiness, and because of it we do not feel the taste of life. Just 'eat and drink for tomorrow we may die' (Isaiah 22:13). This has become the motive of life. If a person does not attain his lust he is ready to kill someone. Even himself and his best friend".
} 
negligible minority that many believed would soon vanish. Limiting the young men to the confines of the yeshiva was perceived as the only way to "save" the community. Such fears play little role today.

Thus it transpires that, despite the rabbis' attempts at supervision, the years of learning in a yeshiva, especially over the last decade, have gradually come to exhibit attributes of a moratorium from binding social control and obligation (Erikson 1968). Thus the young Haredi youth, far from their homes and prior to marriage, enjoy relative freedom and diverse experiences. It is far easier than before to venture into the public domain of the general Israeli society, where one is exposed to new ideas, including far more permissive perceptions of the body. All these add difficulties to the attempt to restrain physical needs and urges. They are also likely to intensify the difficulties experienced by some of the yeshiva youth when modeling themselves on the ideals of the Torah sages peering at them from the accepted biographies. This, in turn, reinforces the demands of Haredi educators to create alternative and more "human" ways of representation and memory.

\section{The Rulings of Torah Sages}

Other factors related to the wider social-historical context influencing the status of Torah sages should also be mentioned. Modernity with its accompanying technological and political upheavals also brought dramatic demographic changes to traditional Jewish societies, among them massive waves of immigration from small towns to the major cities, and from Eastern Europe to Western Europe and the USA. These processes contributed towards a decrease in loyalty towards tradition, especially towards the unique traditions of the various Haredi subgroups. Secondgeneration immigrants tended to unite around a shared Haredi core identity, as expressed through the appearance of the World Agudat Yisrael Movement (Friedman 1991, p. 146). ${ }^{23}$ Agudat Yisrael was headed by the Torah Sages Council (Moetzet Gdolei Ha'Torah). The Council's decisions were supposed to express the Torah View (Da'at Torah). ${ }^{24}$ The term itself express the perception that the "Divine spirit rests on the sages" and that they enjoy a unique personal attribute (charisma) that grants their beliefs and teaching validity beyond that arising from the reasoning capacity of regular human beings (Friedman 1991, p. 105). Friedman also writes that these assumptions are not totally alien to traditional Jewish society, but at the same time he stresses that:

There is no doubt that this is a new social-religious phenomenon which developed against the background of secularization and modernization in 19th century Europe. Facing these processes, the Jewish community had to find urgent answers to new political and social questions and make crucial

\footnotetext{
${ }^{23}$ World Agudath Israel (The World Jewish Union), usually known as the Aguda, was established in the early 20th century as the political arm of Ashkenazi Torah Judaism. Its base was in Eastern Europe but it included participants from Orthodox Jewry throughout Europe.

24 The word da'at in Hebrew means knowledge and the term Da'at Torah means "Torah" view which the Council members are thought to express.
} 
decisions about its relationships with the surrounding non-Jewish community. The traditional answers seemed to be irrelevant in the new incipient reality. Jewish politics, in the broader sense of the term, turned into an autonomous sphere, not connected to the basic assumptions of traditional Jewish politics about exile and redemption. These changes promoted the rise of a new social and political elite group-the Maskilim-which further marginalized the traditional rabbinic leadership. The starting point of the new Haredi organization was an attempt to return the rabbis to politics. The rabbis' restriction to the confines of traditional Jewish culture and their focus on Torah studies engendered a paradoxical explanation: not only did this not decrease their ability to lead their followers, but it was this very preoccupation that granted them extra knowledge and understanding which allows them to see deeper and further than other mortals (Friedman 1991, p. 106). ${ }^{25}$

The unification of the Haredi world, and especially their enclosure behind the walls of the yeshivas, enabled the Haredi society of scholars to grow and flourish (Friedman 1991). As a consequence of that enclosure, tendencies towards conformism and intellectual and social collectivism strengthened, leaving much less room for fresh and original thinking, in sharp contrast to the Lithuanian yeshivas before the Holocaust (Breuer 2004, pp. 485-486). ${ }^{26}$ The Haredi community as a whole became conformist and the Torah sages became, in many aspects, like heads of Hassidic courts, demanding full obedience to their rulings.

Over the past several decades, the Israeli Haredi community has grown demographically and politically, producing an unprecedented number of yeshivas and yeshiva students. The self-confidence of the Haredi individual increased as well. These processes gradually decreased the sense of urgency and danger, as well as the need for unity and conformity, especially in relations with the surrounding nonHaredi community. Consequently, Haredi subgroups, especially Hassidic ones, now sought new ways to express their unique identity and culture. Such fissionary processes were expressed through the establishment of new educational institutions, newspapers, parties as well as additional councils of Torah Sages. As a consequence, the number of Torah Views grew as well. The status of the Agudat Yisrael Torah Sages Council gradually declined, and its meetings became rare. Since the beginning of the 1990s, many new Haredi journals and newspapers appeared, which were independent of Haredi political parties and less rigidly controlled by rabbis. They voiced much stronger internal criticism, both of the Haredi political leaders as well as of the rabbis. Haredi internet forums increased this tendency, by allowing a relatively safe medium for the voicing of internal

\footnotetext{
25 For more about the causes to the formation of the concept of Da'at Torah see Friedman (1991, pp. 104-107), Katz (1992, p. 19), and Brown (2005).

26 Another prominent researcher who wrote about the changes in the status of Rabbis following the Holocaust is Haym Soloveitchik (1994), who focuses on the American Haredi community. He points out that the Haredi community reacted in response to the freedom of choice that became part of Jewish reality in the modern era, in an attempt to counter this confusing freedom and protect its members from it. One way of doing this was by committing many of the oral traditions to writing. As part of this process the rabbis' status increased, as they were recognized as the only official and legitimate interpreters of the texts.
} 
criticism. ${ }^{27}$ New groups and organizations arose, which were not under rabbinical supervision, and, hence, undermined rabbinical authority,

In this environment, the maintenance of the perception that Torah sages are blessed with unique intellectual abilities and perceptions becomes more difficult, especially when resources are scarce and the communities' material and economical needs are growing. The rabbis heading the different communities find themselves obligated to defend their communities' varied interests and often become involved in heated struggles which expose their less spiritual and more human traits. ${ }^{28}$ The relatively unknown aspects of the rabbis' lives become more easily known, exposing the tensions between pretensions to spirituality and altruistic motivations on the one hand, and the all too human reality, often shaped by interests, impulses, and human weaknesses. The permeation of the Liberal-Democratic discourse from the wider Israeli society to the Haredi community also contributes to the undermining of the rabbis' status (Hakak 2006, pp. 36-42). I claim, however, that all these factors are only a partial explanation for the growing demands for more human representations of Torah Sages of previous generations. I will try to provide a fuller explanation.

\section{New Critical Voices: The Chafetz Chaim's Struggle with the Evil Inclination}

I will now address the new critical voices questioning the description of the Torah sages in Haredi biographies. The first to refer to the subject seems to be Rabbi Yitzhak Hutner, ${ }^{29}$ the author of the book Pachad Yitzhak ("Isaac's Fear"), who wrote, in one of his responses to a yeshiva student (Igeret 128):

It is a great evil that, when we deal with the perfection of our outstanding personages, we relate to the summit of their achievement[...]. We recount their perfection while overlooking the spiritual struggle they waged. Our discussion of these personages, gives the impression that they were made by the "hand of the potter" - that they are flawless in stature and character [...]. All praise the purity of speech of the author of the "Chafetz Chaim". But who knows of the battles, the struggles, the obstacles, the failures and the setbacks experienced by the Chafetz Chaim in his battle with his evil inclination. The result is that when a spirited, ambitious, effervescent youth encounters obstacles and failures, he sees himself as not "planted in the house of G-d". For in this lad's imagination, to be planted in the house of G-d means sitting serenely in lush pastures and enjoying his own good inclination just as the

\footnotetext{
${ }^{27}$ A good example of the internet's growing centrality for young Haredi people is the extremely successful and lively Haredi forums in Hydepark-The Israeli Forum Center, the most popular of them'BEHADREY HAREDIM' - 'In Haredi Rooms': http://hydepark.hevre.co.il/forum.asp?forum_id=771.

${ }^{28}$ Friedman describes such a process as a factor that caused the disintegration of the Agudat Yisrael Sages' Council (1991, p. 112).

${ }^{29}$ Rabbi Yitzhak Hutner (1906-1980) headed the Rabenu Haim Berlin Yeshiva in Brooklyn, NY, and was one of the most important Haredi leaders in America during the 20th century. Under his leadership, his yeshiva became a leading institution and was considered as belonging to the same league as its Eastern European predecessors.
} 
crowned righteous enjoy the radiance of the Shekhina in the Garden of Eden, while on the other hand, never being disturbed by the storms of the [evil] inclination... (Hutner 1981, p. 217).

Rabbi Hutner strongly objected to the tendency to glorify Torah sages while obscuring the difficulties facing them on their trail to greatness. Such a one-sided description is liable to greatly frustrate young men at the start of their obstaclestrewn path, in their attempt to cope with impulses, urges, and attributes not mentioned in the literature describing the lives of the sages. The reference to these matters is made in a letter to a student, part of a corpus that may easily be overlooked. It would seem, however, that Rabbi Hutner touched on a burning issue which became far more central for later writers. In recent years, his letter has become particularly popular and many yeshivas photocopy it and distribute it to their students during their entry examinations to adult yeshivas. ${ }^{30}$

In 1997 Rabbi Yaacov Friedman's ${ }^{31}$ book entitled Nefesh HaYeshiva ("The Soul of the Yeshiva") was published, one of the first books dealing openly with the anguish of yeshiva students. He devotes an entire chapter to this topic at the beginning of which he recounts:

A great genius of the generation...spent several weeks in the shelter of a certain yeshiva [...]. After a brief trial period, he left and returned to his parents' home. Many amazing interpretations have been given to his coming and going. But all ignore the correct interpretation that was problematic for the authors of the biographies of Torah sages. The correct explanation was told to the writer of these lines almost in secret: he missed his father's home, and his emotional and shy character drew him back [...]. This chapter warns us of a situation, that I too often abet: when raising the subject: I use tricks to obscure the name of the character and the place of the event. And this is bad [...] because we have been brought up to think that great people are born into a state of holiness and into armoured seclusion [...]. We have been educated to

\footnotetext{
${ }^{30}$ Prof. Ze'ev Lev, a pupil of Rabbi Yaacov Kamenetsky, discusses this issue further in Hama'ayan, the magazine published by Poalei Agudat Yisrael. "Recently, more books have appeared that portray the lives of the Torah sages of past generations. These books are written based on one infantile template. I have personally met many Torah sages of the last generation. I can testify that most of these books are a mixture of truth and falsifications. They portray a genius who at an early age knew some of the Talmud by heart, and studied with great dedication. At the age of Bar Mitzvah they have already delivered sermons before Rabbis, etc. There is no distinction, knowledge or understanding of the sages' personality or internality, his deliberations and doubts[...]. A book was recently published on the Gaon Rabbi Moshe Feinstein, of blessed memory, wherein it says that the Rabbi never read a newspaper in his life. This is rubbish[...]. One rabbi from Bnei Brak wrote recently...that the Chatam Sofer spoke Yiddish and did not study any subjects apart from Torah. The evaluation written by his son in German bears evidence that his father spoke and wrote in German and studied various subjects such as arithmetic and general German culture[...]. These are but a few examples, and not the most flagrant, of intentionally eliminating important facts from the public eye[...]. Why is there no call for the truth? One cannot correct the distortions later, since the Torah public becomes educated in falsehoods through these publications. A person educated with falsehoods finds it hard to correct his opinions" (Hama'ayan 1992, 32(4): 44-49; quoted in Assaf 2006, pp. 33-34, footnote 30).

${ }^{31}$ Rabbi Yaacov Friedman grew up in Lithuanian yeshivas and is a writer and a publicist considered as reflecting the Lithuanian state of mind and its way of thinking. His books are very popular among yeshiva students from all Haredi sectors.
} 
think that a great person cannot yearn, cannot have crises [...]. Of course, he does not wear pyjamas, and does not worry about his income[...]. The writer of these lines could have composed a best-seller of everything he was forbidden to write, everything distanced and concealed under colourful cellophane[...]. All that we, through our short-sightedness, imposed upon the rabbis who enlighten our paths. (Friedman 1997, pp. 111-113).

The emotional motives that led the respected Torah personality to leave the yeshiva did not occur to his biographers, or if they did, they were considered unsuitable or incompatible with the accepted way of writing about such personages. Later, Rabbi Friedman quotes Rabbi Hutner on the subject and finally decides to take courage and reveal that the emotional person who missed home was none other than the Chazon Ish (Rabbi Avraham Yeshayahu Karlitz), the Haredi ideological leader responsible for shaping the Haredi community in Eretz Israel. ${ }^{32}$

Rabbi Hutner's comments continued to make waves. Rabbi Yechiel Ya'acobson, ${ }^{33}$ amongst the most prominent Haredi educators, also referred to this issue. In his lectures, he would often proclaim that "one should remove the Torah sages from the Burial Society," when hinting at the fact that their current description in Haredi biographies causes children and youth to despair and in fact "buries" them alive. Rabbi Ya'acobson claims in his lectures that "one cannot educate through lies" and mentions that the Bible and the Talmud are replete with uncomplimentary descriptions about the nation's illustrious figures. ${ }^{34}$ Another educator to relate to the subject was Rabbi Yitzhak Hershkowitz, ${ }^{35}$ in his book She'ifot ("Strivings") (2003, p. c) he devotes the 14 pages of the introduction to his voluminous book to shattering the delusion regarding the path of the Torah sages. As part of this effort, he introduces tales that testify to Torah sages' struggles with the evil inclination and to the immense effort they had to invest in in order to become renowned in Torah. Thus, for example, he offers comments made by the Vilna Gaon to his student, the Magid MiDubnow, who asked to be bestowed with his evil inclination. In reply to the request, Hershkowitz quotes the Vilna Gaon as saying (2003, p. 3): "My child, may the Lord protect you from my evil inclination; it burns in me like fire!" On page 6, under the heading "Most Torah Sages Did Not Have Talent" he describes the tremendous efforts that befell whoever became a Torah sage and the travail that was the lot of those achieving this status. On page 2 he clarifies:

\footnotetext{
32 Avrohom Yeshaya Karelitz (1878-1953), popularly known by the name of his magnum opus Chazon Ish, was born in Belorussia and became the leader of Haredi Judaism in Israel. He spent his last 20 years, from 1933 to 1953, in Israel.

${ }^{33}$ Rabbi Yaacobson grew up in Lithuanian yeshivas. He heads the Lev Shomea (The Listening Heart) Organization that works with dropout Haredi youth, as well as the yeshiva for young men in Zikhron Yaacov. He is considered by the Haredi community as the biggest expert on Haredi dropouts, as someone who made many breakthroughs in this field and brought the subject to public awareness. His recorded lectures are extremely popular.

${ }^{34}$ These comments were again made in a conversation between this author and Rabbi Yaacobson.

${ }^{35}$ Rabbi Yitzhak Hershkovitz is a Hassidic educator. His book Sheifot ("Aspirations”) became highly popular among yeshiva students from all Haredi sectors.
} 
Righteous people and Torah sages do not become such through signs and wonders, but due to much effort and ongoing toil. They worked on their attributes, polished them, until they shone like diamonds; they worked day and night studying the Torah until they became genii; they struggled with the same evil inclination as we (emphasis in original - $\mathrm{YH}$ ); and repeatedly overcame it until they crushed it; they were tested with difficult trials and overcame them, and thus they grew to become righteous people, genii, sacred and pure.

The path of Torah sages, according to Rabbi Hershkowitz, was no simpler and no different from that of the average yeshiva student. Like everyone else, they, too, were forced to handle many difficulties. The authors mentioned here all emphasize in diverse ways that the "sages" of past generations struggled with their evil inclination no less, and perhaps even more, than any average yeshiva student. How do we account for the change in Haredi educators' description of the sages?

\section{Competition between Yeshiva Students}

The phenomenon of students dropping-out of Haredi educational institutions, which looms as a central threat to the enclave, also holds a key position in the recent Haredi educational literature. In many of the Haredi educational books that I have analyzed, the dropout phenomenon offers a vital, and sometimes the only, link to current circumstances. Since this literature focuses almost solely on the education or the dropping-out of males, it is appropriate to start with a description of the historical development of the world of Haredi yeshivas. This portrayal will help us understand the demand raised by Haredi educators for creating new ways of presenting of the significant past.

An important element in the life of yeshiva students is the means of assessment of their talents and achievements. The subject of competition in Torah study among yeshiva students and among the various yeshivas has always been characterized by great ambivalence in the "yeshiva world." On the one hand, competition enjoyed a key role, and was often accompanied by aggressive or violent manifestations. The yeshivas were intended to produce Torah sages and spiritual leaders, and their proficiency and casuistry were always factors determining the students' social status, the status of the marriages arranged for them, and the positions they would enjoy; these factors encourage competition. On the other hand, learning in itselfthe commandment to study Torah for its own sake-always held an important and very central place, regardless of the students' achievements or the other rewards accruing from this learning.

In the wake of modernization, practices used by the Western education system, such as tests, prizes, and division into levels intended to organize assessing achievement, began to filter into the yeshiva education system and encourage competition and excellence, even if they never became central (Stampfer 2005). ${ }^{36}$

\footnotetext{
${ }^{36}$ For other effects of the universities and the modern Western education system, see Breuer (2004), p. 230.
} 
This process slowed, though it was not abolished, following the Holocaust and the establishment of the State of Israel. After World War II, Haredi Jewry found itself shattered and fragmented, at a time when it was forced to compete with secular Zionism at its peak of strength. In order to survive the new threats, the various streams united (including all the various Hassidic courts and Lithuanian streams) around a common Haredi identity. Considerable effort was invested in blurring Haredi subdivisions, while emphasizing Haredi unity vis-à-vis the intimidating outside (Friedman 1991). As part of this tendency, the equality among members of the community was stressed. One example may be seen in the question addressed by Rabbi Yossef Cahanman, ${ }^{37}$ head of the Ponevich Yeshiva to the Chazon Ish (Rabbi Avraham Yeshayahu Karlitz), as to whether he could found a yeshiva for outstanding students. The Chazon Ish replied in the negative, explaining that all yeshiva students were equal, and should be treated as such. On another occasion, Rabbi Shlomo Lorenz suggested the founding of yeshivas for students of different levels. Again, the Chazon Ish replied in the negative, explaining that every student should have an equal opportunity to become a Torah sage, and by classifying students into differing levels the egalitarian principle would be abolished (Yevrov 1999, vol. 2, p. 40).

It seems that this policy resulted in the expansion and flourishing of Haredi yeshivas. According to Mordechai Breuer, a historian of the yeshiva, within two decades after the Holocaust, there were more Torah students in the USA and in Israel than there had been in Eastern Europe prior to World War II. The demographic growth of Haredi society and its political intensification resulted in heightened self-confidence. Over the course of the following decades, the internal unity weakened and the united Haredi identity gave way to particular Haredi subidentities (Friedman 1991). Differences in economic status also grew. The considerable growth in the number of students was also accompanied by serious fears over student quality. Haredi leaders expressed concern over the ability to pave the path for Haredi life in Israel, when, as the Chazon Ish put it, "the yeshivas in our times abolished the ignoramuses but at the same time, also the Torah giants" (Breuer 2004, p. 484). Since the mid-1980s, these reasons apparently facilitated or even motivated the establishment of several new yeshivas for outstanding students. In response, many yeshiva heads have recently begun to employ the services of "headhunters," whose task is to locate outstanding students in yeshivas for younger boys and persuade them to join their yeshivas. In return, they receive a fee of US\$ 500-1,500 for recruiting the best student in the group (Kook 2005). These are but some of the developments that have increased competition in the yeshiva world in recent decades.

It is important to note that the tension between equality and excellence is one of the educational and philosophical dilemmas in the modern Western education system (Hallinan 2000; Lynch 2000; Ramirez 2001; Yair 1994). In the 1950s, 1960s, and 1970s, the dominant perception promoted the creation of egalitarian educational frameworks, which would afford equal opportunities to all segments of

\footnotetext{
$\overline{37}$ Rabbi Yossef Cahanman made a crucial contribution to the development of the Haredi world of Torah after the Holocaust. For more on that issue, see Friedman (1991, p. 47).
} 
the population and create social integration. Equality in education was perceived as the only way to cast a uniform and shared social basis in countries faced with mass migration, increasingly heterogeneous populations, and conflicting status interests. The dominant educational approach changed completely in the 1980s, as education systems throughout the modern world began to emphasize the striving for excellence over equality (Berube 1994; Mckenzie 2001; Yair 1994).

The increased competition sharpened the lines of social stratification within and among the yeshivas themselves and clarified the connections between achievements in Torah studies and social status, a good match and a well-paid rabbinical position. Many students located on the yeshivas' margins, and therefore also on the social periphery, began to express their dissatisfaction, and the number of dropouts grew rapidly. Many of those who did not excel and find satisfaction through learning Torah began seeking more satisfying areas of activity, usually in the material and earthly domain. The extensive recent educational literature calling for alternative representations of Torah sages emerged in the last decade in response to this rising dropout rate. The educational counselors and rabbis, who met with many of the dropouts, became more sensitive to their critique of the "inhuman" educational models to which they were introduced. The ongoing permeation of the psychological-therapeutic discourse into Haredi society (Finkelman 2008a; Hakak, under review) also helped to increase understanding of the fears, inhibitions, and impulses of their young charges, and the wide gap between the students' reality and the perfect educational models with which they were presented.

While describing the Haredi educational picture of reality, I mentioned the tension inherent in ascribing to Godly ideals which only few could fulfill. One can be a member of the Haredi community even if one does not fulfill all the religious ideals, as long as one continues to aspire to them and conceals one's failures. One way to interpret the new critical voices presented here is to see them as an influence of the Western psychological discourse which attempts to reduce tensions between reality and personal aspirations, while viewing concealment and repression as negative. Deep gaps between aspirations and reality and the need to conceal and repress are considered a target for "therapy." Humans, according to Western psychology, should come to terms with their reality as far as possible, accept themselves with their weaknesses and failures, and be frank about it, without concealing anything. The permeation of this psychological discourse into the Haredi society (Finkelman 2008a; Hakak forthcoming) could form another part of the explanation for the calls not to conceal different aspects of the sages' lives, thus rendering such shortcomings more legitimate within the lives of the students as well.

\section{Anyone Can Be a Torah Sage}

The call to describe the Torah sages in a more human light is, to a large extent, only a development of the far more basic and ancient claim that is primarily addressed to the community of learners, and according to which anyone can become a Torah sage, including those who are not particularly talented. This issue is discussed at 
length in the instructional literature for yeshiva youth and Torah students. It is customary, in this context, to mention Rabbi Akiva, ${ }^{38}$ who for years did not study Torah at all. "He was not born a genius, and was not a member of a distinguished family, but one day he began...with wondrous devotion he invested all his energies-until he became the great Tana, Rabbi Akiva!" (Hershkowitz 2003, p. a). ${ }^{39}$ Comments by Rabbi Moshe Ben Maimon ${ }^{40}$ are also mentioned frequently (quoted by Hershkowitz 2003, p. 187): “The crown of Torah-is there and at the disposal of all of the Children of Israel, as it is said, 'Moses commanded us a law, an inheritance of the congregation of Jacob'. Whoever wants can come and take part". And Hershkowitz adds ( 2003, p. 187);

Everyone who wants... whether he has little talent or whether he is a prodigy[...] Accordingly, even if it seems that you have been born with little talent you can attain greatness in Torah as have all others with talent....and become a sage of the generation!! For the Torah makes the naïve person wise-and hard work and studying Torah will improve even your talents!!. ${ }^{41}$

The attempt to describe the rabbis in a new and more human light would seem to be a contemporary manifestation of this promotion of equality-the status of sage is, in potential, open to all. As I have noted earlier, one of the main ways in which the enclaves try to prevent dropping-out is through the use of a discourse that emphasizes the equality between its members. In the new Haredi educational literature, sages undergo constant struggle with their evil inclinations and cope with the difficulties and obstacles in their path. Achievement is dependent only on the determination and effort of the individual. The role of economic, social, cultural, and family factors is not mentioned. The possibility of becoming a sage undergoes democratization; the illusion, according to which becoming a sage is feasible for all, ${ }^{42}$ is reserved, and the tendency to view the study of Torah as the normative and

\footnotetext{
38 Akiba ben Joseph (ca. 50-ca.135 AD), or simply Rabbi Akiva, was a Judean tanna (Mishna scholar) of the latter part of the first century and the beginning of the second century (third tannaitic generation). He was a great authority in the matter of Jewish tradition, and one of the most central and essential contributors to the Mishnah and Midrash Halakha. He is referred to in the Talmud as "Rosh laHachomim" (Head of all the Sages).

39 Quotations in a similar vein may be found in Wagshal (1982, pp. c-e) and Schwartz (1978, pp. 32, 91). In Hershkowitz (1993), they are particularly prominent.

40 Rabbi Moshe Ben Maimon (1135-1204), Maimonides, was an influential Jewish philosopher and theologian who lived in Spain and is the author of the Guide for the Perplexed.

41 For more on this issue, see Hakak (2005, p. 43) and Hershkowitz (1993, pp. c-d).

42 The fact that one cannot anticipate which student will become a Torah sage is derived from this mystical approach. This attitude has implications not only for Haredi yeshiva students, but also in the debate regarding the desired number of married yeshiva students. Thus, for example, in the wake of the wave of cutbacks in government budgets in 2003, an article appeared in the weekly Mishpacha magazine, entitled, "Whither the Kollels?" (Yeshivas for married students). The author notes that, in view of the series of stringent cutbacks, Haredi society must organize itself accordingly. He suggests raising the threshold of acceptance to kollels so that only prodigies and the talented will study, while others will be directed to the workforce. It would thus also be possible to significantly increase the living stipends for those students remaining in the Torah institutions. The article aroused angry reactions from conservative circles, headed by Yated Ne'eman. Natan Grossman, the editor of that paper, decried the proposal (19/12/03) as selection, "according to the opinions of householders," i.e., the opinions of
} 
sole way of life is maintained with redoubled force. This approach is expected to increase the pressure on individuals, as well as the frustration and feeling of failure of those who are unsuccessful, whose low achievements are interpreted accordingly as the result of lack of effort or lack of real desire on their part.

\section{Summary and Discussion}

I have presented testimony to the awakening voices that sharply criticize biographical writing on Torah sages of previous generations, and have attributed this trend to changes experienced by Haredi society: the increased competitive trends within the Torah world; the demographic growth and increased self-confidence that reduce the need for maximum seclusion, and expose Haredi youth to new, Western discourses regarding the body and the material aspects of life. These changes intensify social stratification within the Torah world, play a significant part in the growth of the social margins therein, and influence the course of those who drop out.

To cope with these processes, the rabbis developed a sophisticated and complex rhetoric designed to bridge an inherent tension between the preservation of a social structure in which all males study in yeshiva at least for several years after marriage, and the reality in which only a selected few are likely to become future Torah sages. This tension is eased somewhat through the "democratization" of the Torah sage: the rabbis stress that the opportunity to become a Torah sage is open to all, even if only a few actually succeed in overcoming their physical urges and the temptations of the material world. As part of the need to encourage Yeshiva scholars in the changing reality, the Haredi educators and rabbis cited here protest the descriptions concealing the difficulties of the sages and the crises and defeats that were their lot, and promote a more accessible, human portrait of the Torah sages. This new portrait seems to be highly influenced or "inspired" by Western psychology, as described above. Given the reason for the production of these new texts, how likely is it that the demands for generating a fuller and more authentic representation and memory, one more faithful to historical truth, will be met? A partial answer can be provided by examining the fate of the writers I have mentioned. While the letter by Rabbi Hutner became a canonical text, and the books by Rabbi Friedman and Rabbi Hershkowitz also became fairly popular amongst yeshiva youth, the book by Rabbi Kamenetsky was banned and Rabbi Kamentesky was slandered and hounded.

The difference in the reception of these books seems to lie in the nature of these texts and the role intended for them. The books by Rabbis Hutner, Friedman, and Hershkowitz, which protest the prevailing description of the sages, belong to an old genre of religious educational literature intended for yeshiva youth, their parents, and their educators. This style of writing and criticism continues a well-established

Footnote 42 continued

ignoramuses. He quoted Rabbi Shach, who determined that "it is impossible to predict for certain who will be great in Torah and one cannot now determine who is more worthy of help and who less." This principle results in a lack of selection, in order to enable as many students as possible to devote themselves fully to their studies. 
genre of moral literature that also dealt with the education of Torah learners. By contrast, Rabbi Kamenetsy's book belongs to another genre, dealing with the history of the Haredi Torah world and biographies of its leaders, and is exceptional within this context. Furthermore, Rabbi Kamenetsky's book (unlike Rabbi Hutner's) not only deals with the vanquishing of evil inclinations, but describes the sages as people who can err, fall, and fail, even after they were recognized as Torah sages.

It would seem, nevertheless, that this account of the difference in the fate of the books and their authors is incomplete. Douglas's (1986) theory is likely to shed further light in this context. According to Douglas, inherent in the ideal of equality embraced by the enclave are several difficulties. One of them is connected to the challenges of self-management and decision making in a totally egalitarian society. Inevitably, authority and the ability to take decisions are transferred to particular personae. But in doing so, the principle of equality is violated. Sivan et al. (2004, p. 92) shows how different enclave groups solve this issue:

In this realm of authority, the modern character of the enclave is more prominent than in any other domain. Authority is shaped here in a fairly innovative manner. It is awarded to a few individuals and preferably to one person only. Professional education and training will apparently be a consideration in the choice of a leader or leaders, although the decisive factor is charisma: That same, special, super-human charm... "godly mercy" that differentiates this one person...from the other members of the enclave....

In Haredi society, the concept of "Torah View" developed, which reflects the principle that the "Divine spirit rests on the sages"; consequently, they possess a unique personal attribute (charisma) that grants their beliefs and teaching validity beyond any logical consideration of regular human beings (Friedman 1991, p. 105).

If this is the case, it is almost essential that they be described in a superhuman light and as significantly different from other mortals. Every questioning of this description shocks the Haredi world perception and is likely to encounter opposition.

In another study, Douglas (1986) shows that, in order for social structures to safeguard themselves, they need supportive cognitive structures. Accordingly, she shows how many classifications of the world and its components, logical actions, and guiding metaphors, are transmitted to man by his society. This applies to the essential, divinely sanctioned distinction between Torah sages and regular mortals. Douglas also writes that the furious response to the violation of such taxonomic categories is a gut reaction that stems from the commitment to a group, and from fear of questioning its most basic conventions.

In the case surveyed, once the distinctions between sages and ordinary mortals were created, they were further charged with special meaning. The letter of ostracization, quoted at the beginning of this article, describes the sages of preceding generations as angels: "The greatness of their elevation and glory of their dignity is rooted in the heart of every God-fearing Jew." This refers to the Talmudic comment (Tractate Shabbat 112b), according to which "If the early sages are like angels we are like people, and if the first sages are like people we are like donkeys." In the context of the above letter, these words testify to the 
"decline of the generations" and to the abyss between our generation and that of those Torah sages of previous years mentioned by Rabbi Kamenetsky. His book seems to have been interpreted as rejecting the distinctions between Torah sages and regular mortals. While other books mentioned here stress that none of the generation's eminent figures were born with their final greatness and perfection, but had to struggle and strive to attain them, none of the authors questioned the basic differentiation between the "sages" and regular mortals. By contrast, Kamenetsky brings forward evidence regarding the behavior of several Torah sages, both in their adolescence and in their old age, in which they are described as lacking some moral attributes. Kamenetsky also hedges his views, noting:

When presenting facts about great Torah personalities, unusual as they may be, we never can determine unequivocally that they demonstrate weaknesses and faults; being that they may be an expression either of unusual positive qualities or of common human weaknesses, we opt for the former when representing great personalities. In summary, we cannot judge and evaluate the individual acts of Torah personages of former generations-nor, for the same reason, can we resolve our problems in the particular ways they resolved theirs....Yet there is much for us to learn from them: not perfection-which needs no model and which everyone must try to achieve in accordance with his own personality-but their motives and ideals, their truthfulness and wholesomeness, their charity and love of Torah. These serve as beacons in our lives (Kamenetsky 2002, pp. xxix-xxx).

Kamenetsky thus qualifies our understanding of the seemingly less than positive traits of the sages. Our short-sightedness may lead us to interpret as negative that which is in fact positive behavior, but is less accepted and familiar and characterizes only particularly great people. Kamenetsky also clarifies that what we must learn from the sages is not perfection, which needs no model, but rather how their motives, ideals, and the wholesomeness of their worlds may be instructive for the contemporary Torah world. I claim that it is precisely this description, which subverts the key distinction between Torah sages and regular mortals, which threatens the Haredi world view, and hence arouses such vehement reactions.

The furious reactions to Kamenetsky's book indicate that his call for a "fuller," less censored history is perceived as a desecration of the holy in the Haredi world view. The deep delineation between the generations' eminence and the rest of humanity is essential as it affords justification for the special status and authority that the former hold. A fuller description of the generations' sages, with their failings and shortcomings, especially those persisting even after they were acknowledged as sages, undermines their legitimacy, questions the social structure, and therefore encounters angry reactions. We may thus assume that the chances of realizing the rabbi's call and of creating real biographical writing are weak. Most likely, educators will suffice with the continued distribution of Rabbi Hutner's critical letter as a balance to a corpus of biographical writing that will continue unchanged. 


\section{References}

Almond, Gabriel A., R. Scott Appleby, and Emmanuel Sivan. 2003. Strong religion: The rise of fundamentalism around the world. Chicago: Chicago University Press.

Assaf, David. 2006. Caught in the thicket: Chapters of crisis and discontent in the history of hasidism. Jerusalem: The Zalman Shazar Center for Jewish History (Hebrew).

Bartal, Yisrael. 1984. Zichron Yaakov lerabi Yaakov Lifshitz: Orthodox historiography? Malat b: 409414 (Hebrew).

Bartal, Yisrael. 1998. Hayedia Vehachochmah Ha'amitit: Guideline for the understanding of the orthodox historiography. Zmanim 64: 4-14.

Berube, Maurice R. 1994. American school reform: Progressive, equity and excellence movements, 18831993. London: Westport, Connecticut.

Breuer, Mordechai. 2004. Gidulo Shel Gadol. Hamayan 42(2): 81-86. (Hebrew).

Brown, Binyamin. 2005. The doctrine of Torah view: Three stages. In Derech Haruach, ed. A. Yehoyada, 537-600. Jerusalem: The Van-Leer Institute. (Hebrew).

Chodorow, Nancy. 1974. Family structure and feminine personality. In Women, culture and society, ed. M.Z. Rosaldo, and L. Lamphere, 43-67. Stanford: Stanford University Press.

Douglas, Mary. 1986. How institutions think. London: Routledge.

Douglas, Mary. 1993. In the wilderness: The doctrine of defilement in the book of numbers. Sheffield: Sheffield Academic Press.

Erikson, Erik H. 1968. Identity: Youth and crisis. New York: Norton.

Finkelman, Yoel. 2008a. Tradition and innovation in American Haredi parenting literature. In Innovation, change in Jewish education, ed. D. Zisenwine. Tel-Aviv: Tel Aviv University Press.

Finkelman, Yoel. 2008b. Nostalgia, inspiration, ambivalence: Eastern Europe, immigration, and the construction of collective memory in contemporary American Haredi historiography. Jewish History. doi:10.1007/s10835-008-9071-x.

Friedman, Yaacob B. 1997. The Yeshiva's soul: Open hurt to hurt conversations on the world of the son of the Yeshiva. Jerusalem: Torat Chaim Press. (Hebrew).

Friedman, Menachem. 1991. The Haredi society: Sources, trends and processes. Jerusalem: The Jerusalem Institute for Israel Studies. (Hebrew).

Friedman, Menachem. 1993. The Haredim and the Israeli Society. In Whither Israel: The domestic challenges, ed. J. Peters and K. Kyle, 177-201. London: The Royal Institute of International Affairs (Chatham House) in association with LB. Tauris.

Funkenstein, Amos. 1993. Perceptions of Jewish history. Berkeley: University of California Press.

Greenfield, Tzvia. 2004. The Myth of the Subject: Democracy as a Second Rate Theory of Man and World. Ph.D. Thesis (Hebrew), Department of Philosophy, The Hebrew University of Jerusalem, Jerusalem.

Hallinan, Maureen T. 2000. Handbook of the sociology of education. New York: Kluwer Academic/ Plenum.

Hakak, Yohai. 2005. Spirituality and worldliness in Lithuanian Yeshivas. Jerusalem: The Floersheimr Institute for Policy Studies. (Hebrew).

Hakak, Yohai. 2006. Men in black: A journey to the wellsprings of Israeli politics: Haredi men in the Likud. Jerusalem: The Israeli Institute for Democracy. (Hebrew).

Hakak, Yohai. (under review). Psychology and democracy for Godly purposes: Modern discourses on parenting for strictly conservative goals. In Psychology on the sociology's couch, ed. Nissim Mizrahi. Jerusalem: Van leer institute.

Hershkowitz, Yitzhak. 2003. Sheifot. Jerusalem: Private Publishing. (Hebrew).

Hutner, Yitzhak. 1981. Pachad Yitzchok. New York: Gur Arie Institute. (Hebrew).

Kamenetsky, Nathan. 2002. Making of a Godol: A study of episodes in the lives of great Torah personalities. Jerusalem: Hamesorah.

Kamenetsky, Nathan. 2003. Anatomy of a Ban: The story of the Ban on the book "Making of a Godol". Jerusalem: Private Printing Publishers.

Karlinski, Nachum. 1998. Contra history: On the letters of the Hassidim from Eretz Yisrael. Jerusalem: Yad Yitzhak Ben Zvi. (Hebrew).

Karlinski, Shlomo. 2004. The person in His world: Chapters of reflection in the essence, goal and duty of the person in His world. Jerusalem: Private Publishing. (Hebrew). 
Katz, Jacob. 1992. Halacha Bemeytzar: Obstacles on the orthodox path in its formation. Jerusalem: Magnes. (Hebrew).

Klatzkin, Moshe. 2004. Beyni Livni: Practical guidance in the education of children. Part B. Jerusalem: Private Publishing. (Hebrew).

Kook, Shlomo. 2005. The notebook is open and the hand is writing. Bakehila, July 21, 20-21, (Hebrew).

Lahav, Chaim. 2006. Processes and transformations in the endangerment and detachment characteristics of adolescent Haredi youth treated in the units of youth protection. Menituk Leshiluv 13: 27-42. (Hebrew).

Levi, Avraham Y. 2001. Me and the boy: The youth and its passage from Katnut to the Gadlut of the Bar Mitzva age. Jerusalem: Private Publishing. (Hebrew).

Luzzato, Moshe Chaim. 2001. Mesillat Yesharim. Skokie: Varda Books.

Lynch, Kathleen. 2000. Research and theory on equality and education. In Handbook of the sociology of education, ed. Maureen T. Hallinan, 85-105. New York: Kluwer Academic.

Mckenzie, Janet. 2001. Changing education: A sociology of education since 1944. Essex: Pearson Education.

Moyn, Shmuel. 2003. Amos Funkenstein on the theological origins of historicism. Journal of the History of Ideas 64(4): 639-657.

Ramirez, Francisco O. 2001. Mass schooling. In Education and sociology: An encyclopedia, ed. David L. Levinson, Peter W. Cookson Jr, and Akan R. Sadovnik, 429-434. London: Routledge.

Roze, Aharon. 2006. The Haredim: A defense. Azure, 25: Summer 5766.

Satlow, Michael L. 1996. Try to be a man. Harvard Theological Review 89(1): 19-41.

Schwartz, Yoel. 1978. The son of Torah and the Yeshiva: A compendium of guidance and consultation issues. Jerusalem: Yeshivat Dvar Yerushalim Press. (Hebrew).

Shach, Menahem E. 1993. Guidance for the Yeshiva student: Letters and articles. Bnei-Brak: Published by the Rabbis' students. (Hebrew).

Shlanger, Menachem. 2001. Sefer Sha'arei Gdula. Jerusalem: Private Publishing. (Hebrew).

Sivan, Emmanuel. 1991. The enclave culture. Alpaim 4: 45-98. (Hebrew).

Sivan, Emmanuel, Gabriel A. Almond, and Scott R. Appleby. 2004. Modern religious fanaticism: Judaism, Christianity, Islam and Hinduism. Tel Aviv: Chaim Hertzog Center for the Research of the Middle East and the Diplomacy. (Hebrew).

Stampfer, Shaul. 2005. The Lithuanian Yeshiva in its formation. Jerusalem: The Zalman Shazar Center. (Hebrew).

Wagshal, Shaul. 1982. Orchot Yesharim Vesepher Leben Yeshiva. Gateshead: Private Publishing. (Hebrew).

Wilhelm, Nachman Yossef. 1993. Doron Drasha. Jerusalem: Drosh Noy Institute. (Hebrew).

Yair, Gad. 1994. Between social equality and excellence: The contribution of the parents' social background to the educational achievements of the students in formal and informal classes. Ph.D. Thesis, The Hebrew University of Jerusalem, Jerusalem.

Yerushalmi, Yoseph Chaim. 1982. Zakhor: Jewish history and Jewish memory. Seattle: University of Washington Press.

Yevrov, Zvi. 1999. Maase Ish: The life story and guidance of our Rabbi Avraham Yishayahoo Karelitz the Author of Hazon Ish. Bni-Brak: Private Publishing. (Hebrew). 